stomatologie $2013 \cdot 110: 36-36$

DOI 10.1007/s00715-013-0234-0

C Springer-Verlag Wien 2013

\author{
H. Haider \\ Österreichische Gesellschaft für Zahn-, Mund- und Kieferheilkunde, Markt Allhau
}

\title{
Zahnerhaltung versus Implantologie
}

\section{Kommentar zu „,Wie löse ich diesen Fall!?" aus stomatologie 1-2/2013}

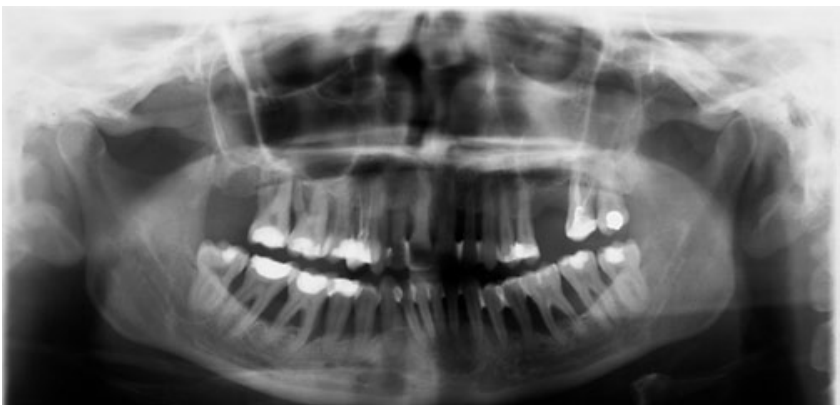

\section{Korrespondenzadresse}

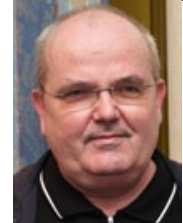

Prof. Dr. H. Haider

Österreichische Gesellschaft für

Zahn-, Mund- und

Kieferheilkunde

Gemeindestr. 29/5,

A-7411 Markt Allhau

herbert.haider@live.at

Danksagung. Mein Dank gilt Frau Dr. C. Bruckmann die diesen Fall 2009 bei einer Fortbildungsveranstaltung in Wien präsentierte und die Unterlagen freundlicherweise für diese Rubrik zur Verfügung stellte.
Abb. $1<$ Orthopantomogramm des Patienten aus dem Jahr 2011

Unser Fach ist so umfangreich geworden, dass es niemandem mehr mög lich ist, alle Teilbereiche perfekt abzudecken. Bei auftretenden Problemen, die nicht selbst ganz beherrscht werden können, sollte in jedem Fall professionelle Hilfe eines spezialisierten Kollegen in Anspruch genommen und der Patient einer geeigneten Therapie zugeführt werden. Im Regelfall kommen die Patienten dankbar zum überweisenden Zahnarzt zurück, weil er in seiner Kompetenz das gravierende Problem erkannt und rechtzeitig zu einem Spezialisten überwiesen hat. 